\title{
Conceptualizing Urban Economic Resilience at the Time of Covid-19 and Beyond
}

\author{
Dmitry Pozhidaev \\ United Nations Capital Development Fund (UNCDF)
}

Economic resilience has been identified as the key factor that defines the ability of urban communities to cope with the consequences of the ongoing COVID-19 crisis as well as any other global health-related economic shocks. This paper offers a dynamic action-oriented concept of urban economic resilience defined as the capacity and related capabilities of urban communities to plan for, anticipate negative shocks, including long-term stresses, to their economies, reallocate and mobilize resources to withstand those shocks, recover from the shocks, and rebuild at least to pre-crisis levels as soon as possible, while placing their economies on the path to sustainable economic growth and simultaneously strengthening their capacity to deal with any future shocks. the paper suggests key operational indicators for the identified variables and discusses how the conceptual framework presented in the paper can be used to measure urban economic resilience and assess city performances.

Keywords: COVID-19, urban economy, economic resilience, performance measurement

\section{CONTEXT}

This paper presents an attempt to operationalize the concept of urban economic resilience in the context of the ongoing COVID-19 pandemic.

As will be discussed further, resilience is a broad concept and so is the approach to COVID-19 recovery as presented in the UN Framework for the immediate socio-economic response to COVID-19 (2020) and a multitude of regional, national and local recovery strategies and plans, which encompass various economic, social, environmental and health aspects of recovery. Characteristically, most of these strategies and plans refer to resilience as a key feature that determines the shock absorptive and recovery capacity to an extent where even regional structures crave for more resilience, such as the EU whose recovery plan sets the task of building "a more sustainable, resilient and fairer Europe for the next generation" (EC 2020). Schwab and Malleret (2020: 19) emphasize the global dimension of resilience, urging to "take advantage of this unprecedented opportunity to reimagine our world, in a bid to make it a better and more resilient one as it emerges on the other side of this crisis". The same message is reflected in the strategies and action plans of individual cities: for example, the COVID-19 action plan for the city of Barcelona emphasizes a strategic goal of implementing new models to make Barcelona a more resilient city (City of Barcelona 2020).

As regions and countries, and often different localities within the same countries, demonstrate at times stunning differences in the impacts produced by the pandemic, ${ }^{1}$ resilience is evoked more and more frequently as a key explanatory variable for these differences. The pandemic has prompted a surge of 
research to analyze and flesh out the importance of resilience at the global (Noy et al. 2020), regional (Di Pietro et al. 2020, Brada et al. 2021), national and local levels (Gong et al. 2020).

This paper has a much narrower focus on economic and financial recovery in the urban context, which calls for two qualifications with respect to the breadth and scope of the conceptualization of resilience developed in this paper.

The first one is focus on the economic and financial dimension of resilience. As this paper will further analyze, resilience has more dimensions than just economic. For example, the World Bank (2013) identifies four dimensions: infrastructural, institutional, economic, and social. Similarly, economy is just one (and presumably not the most important) of the eight elements of an urban system distinguished by UN-Habitat (2018): Built Environment, Supply Chain and Logistics, Basic Infrastructure, Mobility, Public Services, Social Inclusion and Protection, Economy, Ecology. The City Resilience Framework developed by Arup and Rockefeller Foundation (2015) highlights four aspects of urban resilience: health and wellbeing of individuals (people); urban systems and services (place); economy and society (organisation); and, finally, leadership and strategy (knowledge).

Hence, this paper's focus on the economic dimension of resilience does not imply an underestimation the importance of the other dimensions or aspects of resilience (social, environmental, technological, etc.). This approach (or a particular analytical angle) shapes the answer to the important question about the performance measure because in the words of Régibeau and Rockett (2013), "resilience by one measure need not imply resilience by another". The key performance measures used further to operationalize the concept of urban economic resilience are the local economic output (city gross product), city revenue, employment rate and inequality.

The choice of these three measures is dictated by considerations of practicality as part of a standard microeconomic indicator framework. The author is fully aware of the imperfections of aggregate output indicators as a measure of development recognized, which has given rise to global "beyond GDP movement" to find alternative measures of social well-being (Stiglitz, Fitoussi and Durand 2019). Most problematically, GDP (and its variations) often fail to account for economically productive activities while reporting economic outputs that may be outright damaging to society. However, given the lack of consensus about the alternative measures and generally accepted methodologies for them as well as the current availability of statistical data, our concept uses the four indicators explained above.

This said, to an extent that those other aspects discussed above are relevant for economic resilience, they have been incorporated in the analytical framework and reflected in the indicators (e.g., considerations about environmental and social sustainability of economic activities in the context of sustainable urban future).

The second qualification is related to the uniqueness of the present situation caused by the COVID-19 pandemic, which shapes the response to the question "resilience for what?". Several authors (Régibeau and Rockett 2013, Meerow et al. 2016) have stressed that resilience needs to be contextualized, i.e., we must state the type of shock - mild or severe, specific or broad-based - to which we want our system to be resilient. In this respect, the proposed operationalization refers first and foremost to the COVID-19 shock. It is therefore important to understand the key characteristics and the mechanism of the shock generated by COVID-19.

IMF (2020) explains the mechanism of the COVID-19 shock as follows. "The pandemic is causing local, regional, and global supply disruptions; local and sectoral demand repercussions; and confidence effects holding back demand. Social distancing efforts necessary to contain the spread of the virus have curtailed demand, particularly in tourism, travel, and hospitality services, and have imposed even larger costs on livelihoods and output. Consumer and business confidence has fallen. Commodity prices have declined as a result of both lower global demand and a decision in early March 2020 by large oil producers to increase supply." IMF further notes two other factors: increased cost and scarcity of financing for firms and some sovereigns as well as the adverse effect of disrupted supply and weakened demand on employment and growth, government revenues, and increased strains on countries' public finances. Unlike under normal economic shocks when global and regional supply chains remain operational or a disaster when a particular location drops out of a supply chain due to cessation of its economic activities, the 
pandemic is simultaneously taking place across different parts of the world cutting supply chains and preventing movements of people, goods and services.

COVID-19 is not a usual economic recession although it shares many features with it. The key thing to note about a pandemic (like COVID-19) is that it fundamentally changes the production possibilities set for the economy. According to Gans (2020), the new production possibility frontier (PPF) is characterized by two features. First, the pandemic PPF lies below the normal PPF, implying that it is impossible to produce as much economy or health as before. Second, there is a hollowing-out of the PPF, meaning that the tradeoffs between economy and health become greater, and reaching a pre-pandemic level of one requires giving up a greater amount of the other. Hence, the only way to get a better economy is to give up a great deal of health and vice versa.

On the city and local government level the current COVID-19 crisis is producing the same impacts as the previous broad-based international or regional crises, such as the great recession caused by the global financial crisis of 2008-09 (Paulais, 2009). First, they cause declines in revenue directly affecting local governments' budgets, including own source revenues and transfers from national governments. Furthermore, some of these revenues (such as municipal charges and fees for some services) are intentionally foregone by local governments as part of a local economic relief package for businesses and households (UN-Habitat et al. 2020) Second, an economic slump increases unemployment and increases social welfare needs, the burden of which falls on an already cash-strapped public sector (COVID-19 is creating additional financial burden to establish and maintain an excess healthcare capacity). Third, a sharp decline in financing capacities makes it more difficult to get loans or solicit investment for capital projects. As a result, localities register slower (or even negative) increases in the local output, causing lower living standards and more poverty. Indeed, the most recent growth forecasts for major African cities (UN-Habitat et al. 2020) predict a significant drop in growth rates taking some of them into the negative territory (Figure $1)$.

\section{FIGURE 1 \\ PROJECTED GROWTH AND GROWTH UNDER COVID-19 CONDITIONS IN SELECTED AFRICAN PRIMARY CITIES}

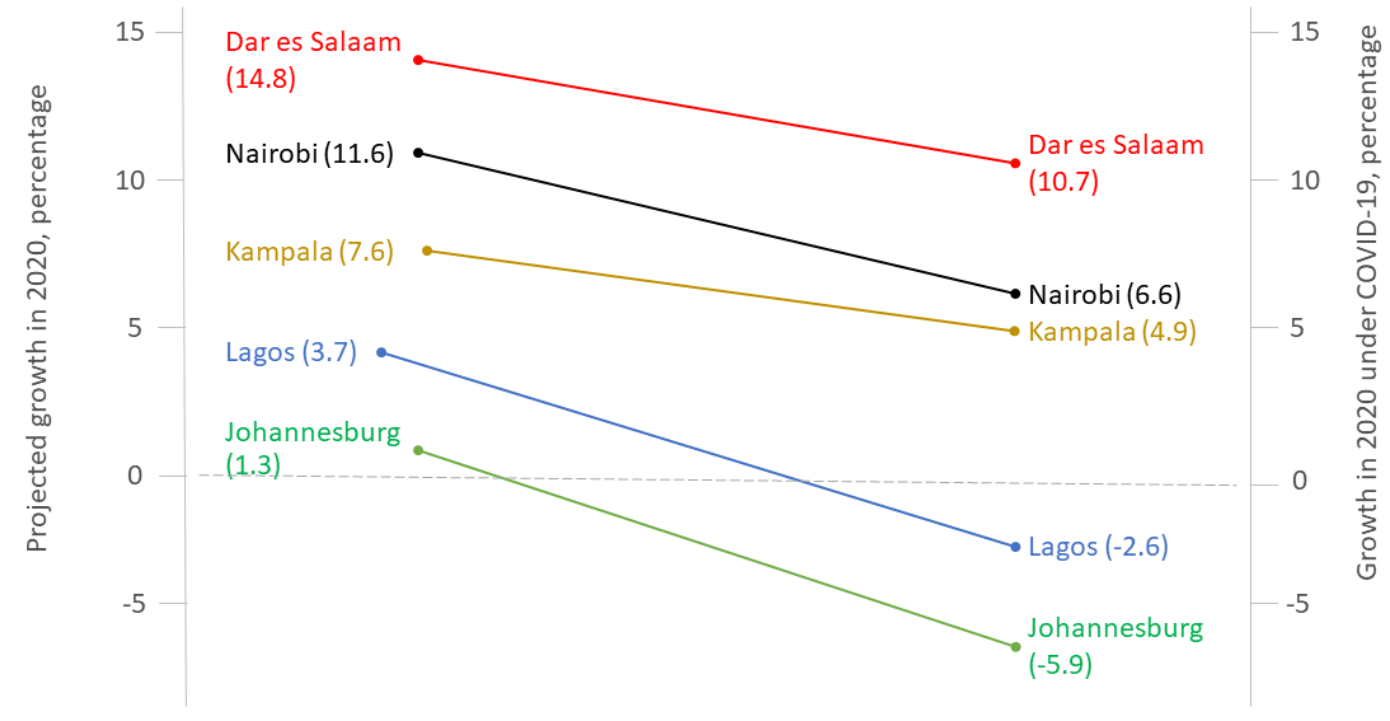

Source: Author's creation

In sum, although it is assumed that many of the approaches to resilience elaborated in this paper are also relevant and valid for other types of shock, at the center of this analysis is a broad-based health-related 
economic shock at a lower production possibility frontier with significant movement restrictions and affecting simultaneously aggregate supply and demand.

From a general methodological perspective, this paper subscribes to the view that resilience is a "highly complex, malleable and dynamic political construct", which "due to its vagueness, now plays a role of a term that facilitates communication across various disciplines and it often creates a perception of a shared vocabulary" (Chmutina et al. 2016). Coaffee and Lee (2016) call resilience "an all-encompassing metaphor" metaphor which can be applied in a variety of national and international contexts. It also takes a position that ultimately only practice is the criterion of truth and the experience of implementing urban resilience policies and programs will "shape and influence our understanding of how the term urban resilience can and should be conceived" (Shamsuddin 2020). From a practitioner's point of view, a fine definition of urban resilience is less important than its potential to guide the activities of local economic actors to adopt and adapt approaches to urban resilience that fit their individual and local needs, capacity, and historical experience.

On the operational plane, this concept of urban economic resilience is based on three principles: (1) distinction between resilience and other closely related concepts, such as vulnerability, sustainability and risk; (2) conceptualization of economic resilience from the perspective of a dynamic action-oriented capability to plan and manage local resources; and (3) situation of economic resilience in the urban context.

Lastly, the paper is practice oriented in two respects. It considers practical experiences of cities to respond to COVID-19 and previous broad-based international or regional crises (such as the 2007 Asian financial crisis, the 2008-09 global financial crisis and the 2014-16 Ebola outbreak in West Africa) to refine the concept of economic resilience. At the same time, it attempts to operationalize this concept in a way that would allow cities to (1) develop an understanding of their resilience, assess their performance and identify strengths and weakness and then (2) design and implement specific practical solutions to improve their economic resilience to future socio-economic shocks. In doing so, this paper subscribes to the view that resilience is a "prime mobilizing concept upon which a host of strategies may converge to help society and cities better prepare for a range of risks across regional, national and global scales" (O'Hare and White 2013).

The paper proceeds as follows. It analyzes resilience and a number of the closely related concepts, such as sustainability, risk, and vulnerability. In the process, it seeks to disambiguate and delineate those concepts to clarify the meaning of resilience. Based on this analysis, the paper then suggests an actionoriented approach to resilience as a set of capabilities for managing economic resources. It further refines the concept in a specifically urban context linking it to the challenge of inclusive and sustainable local development. This is followed by definition of key components of the urban economic ecosystem (business environment; governance arrangements; labour market conditions; financial arrangements; and basic services and connectivity) and a detailed analysis of key causal and indicator variables. Finally, the paper suggests key operational indicators for the identified variables and discusses how the conceptual framework presented in the paper can be used to measure urban economic resilience and assess city performances.

\section{RESILIENCE AND OTHER RELATED CONCEPTS}

Resilience can be described as an essentially contested concept (ECC) par excellence to an extent where some observers believe that the term resilience is "at best imprecise and may simply be replacing other ambiguous and slippery terms like sustainability" (Shamsuddin 2020). ESCAP (2019) notes that the concept of resilience suffers from the "catch-all syndrome", by which resilience "seems to cover every aspect of urban governance and as a result suffers from a paralysis whereby it ends up covering nothing at all". To complicate things further, resilience often appears next to, or in some relationship with, other concepts, such as sustainability, risk, and vulnerability.

Davoudi (2012) argues that resilience may be simply replacing sustainability as another term with widespread appeal despite (or perhaps because of) a lack of clarity. Arup's City Resilience Framework (Rockefeller 2015) recognizes sustainable economy as a critical condition for achieving city resilience but is silent about whether such economy should itself be resilient. However, despite some confusion, the 
distinction appears to be relatively clear. As Régibeau and Rockett (2013) argue, while "resilience relates to recovery of a system from a shock, sustainability relates to the long-term trajectory - or opportunity set - of a social system". In addition, resilience requires definition of a shock to be applied, whereas sustainability does not. Coaffee and Lee (2016:19) sum it up like this: "In essence, where sustainability often assumes a present and future of equilibrium, resilience is based upon a change paradigm, which makes it particularly helpful for managing a complex and uncertain future." This distinction also comes clearly in the UN-Habitat (2017) definition of urban resilience which specifies that resilience should help an urban system to positively adapt and transform toward sustainability.

There are also multiple links between risk, vulnerability, and resilience. Coaffee and Lee (2016) point out that urban resilience requires consideration of multiple risks and hazards in a holistic fashion. In this sense, "resilience goes beyond risk management to address both the interdependencies and the complexities of large integrated infrastructural and service delivery systems premised upon the uncertainty of future threats". By extension, "urban resilience is, in essence, a response to existential or material vulnerability, insecurity and, ultimately, change" (Coaffee and Lee 2016:96). At the same time, vulnerability implies "a measure of risk associated with the physical, social and economic aspects and implications resulting from the system's ability to cope with the resulting event" (Proag 2014). But somewhat confusingly vulnerability is also considered one of the defining components of disaster risk which is defined as a product of hazard, exposure, and vulnerability: $\mathrm{R}=\mathrm{H}$ x E x V (UNDRR 2020). In this context, vulnerability is considered as the susceptibility of people and economic assets to suffer loss and damage to acknowledge the fact that disaster risk not only depends on the severity of hazard or the number of people or assets exposed, but that it is also a reflection of their susceptibility. IPCC (2012) argues that levels of vulnerability (and exposure) help to explain why some non-extreme hazards can lead to extreme impacts and disasters, while some extreme events do not.

On the other hand, Gitz and Meybeck (2012) argue that the three concepts differ in how they impact systems as follows. Risk designates the potential of shocks and stresses to affect, in different ways, the state of systems, communities, households or individuals. The impact of a risk depends on the shock itself but also on the system to which it is applied. Depending on its vulnerability, the system will be more or less affected by the same shock. Depending on its resilience, it will recover more or less easily.

But if the distinction between risk on the one hand and vulnerability and resilience on the other is clearcut, the difference between resilience and vulnerability appears to be less so. Thus, the above discussion suggests that vulnerability refers to the extent of the impact of a shock whereas resilience the ease of recovery. Similarly to the already mentioned claims that resilience is but a shorthand for sustainability, there are also voices claiming that vulnerability is the flip side of resilience (IPCC 2001) because the way to increase resilience is to reduce the existing vulnerabilities.

Others however emphasize the difference between the two concepts. Briguglio et al. (2008) define economic vulnerability as "the exposure of an economy to exogenous shocks, arising out of economic openness, while economic resilience is defined as the policy-induced ability of an economy to withstand or recover from the effects of such shocks". Noy and Yonson (2018) use a broader definition of resilience as "the ability of a system, community or society exposed to hazards to resist, absorb, accommodate to, transform and recover from the effects of a hazard in a timely and efficient manner, including through the preservation and restoration of its essential basic structures, and functions...". This definition covers both the absorption period (which determines the extent of impact) and the recovery period unlike the formula by Gitz and Meybeck (2012) where the two are separated between vulnerability and resilience, respectively. This latter definition also has an expressed action-oriented nature: resist, absorb, accommodate to, transform and recover. However, it connects the system capabilities to the shock itself rather than to resources at the disposal of a system, community or society.

It is a well-accepted view that vulnerability indicates the inherent features of a system (such as exposure, sensitivity, and adaptive capacity) that make it susceptible to damages and disturbances caused by a host of internal and external factors (natural, social, economic, etc.). But while resilience and vulnerability do share certain underlying attributes, such as exposure and sensitivity, they cannot be regarded as a mirror reflection of each other. 
Indeed, if the two concepts were the same, then localities at the same level of vulnerability should demonstrate the same level of resilience. However, the most recent experiences of COVID-19 patently demonstrate that this is not the case. Cities located in the same countries and at a similar level of (economic) vulnerability have differed both in the impact produced by the pandemic and in their recovery trajectories. Furthermore, an approach that equates vulnerability with resilience would imply that more economically developed locations would always outperform less economically developed locations simply because of the formers' access to greater resources to reduce their vulnerability. Again, the practice shows that this is not always the case although in general more advanced locations do demonstrate a better resilience capability. Even within the same countries, less developed (smaller and poorer) locations sometimes performed better than more developed (larger and more prosperous) ones. The same is true for inter-country comparison when some less developed countries demonstrate remarkable examples of high resilience in face of the crisis. Vulnerability is clearly a function of economic development whereas resilience is not.

In practice, the continued confusion between vulnerability and resilience results in very similar or even identical metrics designed to measure these two concepts so that it is impossible to say just looking at the metrics, which one it is intended to measure. Furthermore, equating resilience with vulnerability leads us to a policy cul-de-sac. If vulnerability is the same as the sum of structural characteristics of a locality prior to the crisis (e.g., lack of medical facilities), then there is no point in discussing local resilience because it is fully defined by the existing vulnerabilities. Presented with results of a resilience analysis based on their vulnerabilities, local governments all too often just shrug it off saying that the existing resource envelope does not allow them to implement recommended actions.

The foregoing discussion allows us to return to the distinction between vulnerability and resilience and summarize the key features that distinguish them (Table 1).

TABLE 1

VULNERABILITY AND RESILIENCE: KEY CHARACTERISTICS

\begin{tabular}{lllll}
\hline & $\begin{array}{l}\text { Key features } \\
\text { Determinant factors }\end{array}$ & Specificity & Response capacity & Dynamism \\
\hline Vulnerability & $\begin{array}{l}\text { Determined by } \\
\text { exogenous structural } \\
\text { factors that produce } \\
\text { unsafe conditions }\end{array}$ & $\begin{array}{l}\text { Specific and related } \\
\text { to the underlying } \\
\text { emergency (e.g., } \\
\text { earthquake) }\end{array}$ & $\begin{array}{l}\text { Capacity correlated } \\
\text { with structural } \\
\text { factors and } \\
\text { economic resources }\end{array}$ & $\begin{array}{l}\text { Static, mostly } \\
\text { pre-emergency }\end{array}$ \\
Resilience & $\begin{array}{l}\text { Determined by } \\
\text { endogenous factors } \\
\text { (characteristics of the } \\
\text { ecosystem) }\end{array}$ & $\begin{array}{l}\text { Generic and cutting } \\
\text { across all types of } \\
\text { emergencies }\end{array}$ & $\begin{array}{l}\text { Capacity correlated } \\
\text { with institutional } \\
\text { factors }\end{array}$ & $\begin{array}{l}\text { Dynamic, } \\
\text { before, during } \\
\text { and after the } \\
\text { emergency }\end{array}$ \\
\hline
\end{tabular}

\section{RESILIENCE AS A SET OF DYNAMIC ACTION-ORIENTED CAPABILITIES}

This leads us to a more dynamic concept of resilience based on a range of actions that communities can undertake to "resist, absorb, accommodate to, transform and recover" from the effects of a crisis in a timely and efficient manner. Thus, Briguglio et al. (2008) clearly define economic resilience in association with "actions undertaken by policymakers and private economic agents which enable a country to withstand or recover from the negative effects of shocks". The state of infrastructure and other factors of production as well as the other economic, social, technical and similar factors that determine vulnerability of a city are what they are and obviously cannot be changed in the short run (and may be difficult to change in the medium run as well) but actions to improve the allocative and productive efficiencies of those factors as well as mobilize additional required resources can and should be taken by a responsible local government. ESCAP (2019) notes the global trend to rely less on hard or "grey" infrastructure as a symbol of success 
and development and more on robust solutions that allow full utilization of local capabilities. Similarly, Coaffee and Lee (2016) discussing existing resilience assessment approaches stress the need to enable recognition of capacities and capabilities in addition to physical risks.

Here and in the following text resources are understood as economic resources, i.e., factors of production generally classified as labor, capital, land, or entrepreneurship. Economic resources are the workers, equipment, raw materials, and organizers that are used to produce economic goods. The focus on economic resources is defined by the scope of the joint UN project and without any prejudice to the importance of other resources (such as social capital) as already discussed in the introductory section.

Hence, the empirical definition of resilience developed in this paper is based on an analysis of the capacities and capabilities of local economies and local governments in the above two areas (in the sense of their power or ability to respond to a crisis situation by mobilizing new or reallocating existing resources) plus an additional area related to foresighting resource requirements for future emergencies. This approach covers all phases of a crisis, from preparedness through response and recovery. In other words, what we should be asking is what local economies can do using whatever (limited) resources at their disposal and what factors enable or inhibit such action prior to, during and after the emergency.

The Guide on Measuring Urban Risk Resilience (Earthquakes and Megacities Initiative 2015) rightly described the downside on inadequate resilience: "Lack of resilience is the limitations in access to and mobilization of the resources of the human settlements and their institutions, and the incapacity to adapt and respond in absorbing the socio-ecological and economic impact."

\section{Capabilities for Management and Reallocation of Existing Economic Resources}

To increase the allocative and productive efficiencies of the existing factors, local factor markets should be flexible enough to allow reallocation of resources (labor and capital) across sectors and local economic actors (including local governments) should have enough discretionary powers for such decisions. A typical example during the pandemic was reallocation of local resources towards activities with a higher than usual demand, such as production of sanitizers, handwashing stations, masks and other equipment. There are many examples of producers of beverages and cosmetics, as diverse as l'Oréal in Paris and Blue Nile Distilleries in Uganda switching to production of medical supplies. Whereas capital investment programs have seen budget cuts because of rescheduling or downright resizing, this approach has not been universal across all capital investment projects. In fact, cities that fared better in their COVID-19 response tried to ringfence as much as possible the budgets for projects that would ensure immediate public employment to substitute for a diminished level of overall economic activity while also delivering long term economic benefits to the cities and regions. Thus, the city of Kharkiv has stepped up its housing program, completing 200,000 square meters of residential properties during the first six month of this year, 2.5 times more than in 2019 (UNCDF 2020d).

Those localities that have been able to do it quickly, have been impacted by the economic downturn less and retained more jobs. However, existing business regulations and the state of the labor market may make such a transition impossible. Another example is the power of local governments to reallocate on its own authority financial resources from one budget line to another to provide relief to local businesses. Indeed, no city has been able to navigate through the COVID-19 crisis without reprioritizing and reprogramming their budget. Reprioritization has most affected capital investment programs although many cities (Bishkek in Kyrgyzstan, Kampala in Uganda, Lima in Peru among others) have also tightened their belts in terms of administrative expenses (such as travel, training, maintenance, some personal benefits, etc.) carving out some additional fiscal space. The city of Subang Jaya (Indonesia) has reduced its administrative costs by $20 \%$ (UNCDF 2020d). Cities recognize that the COVID-19 crisis has offered an opportunity to rethink public budgets, particularly administrative expenses, and improve the productive efficiency of public money in line with the principles considered in the previous section.

Of course, local economic resources may differ significantly between various jurisdictions and are determined by their structural characteristics but so may the discretionary powers of local economic actors. Thus, a local government with less resources may have more discretionary powers over their use and reallocation and vice versa: this is the case in the regions where local government powers are curtailed and 
their resources are tightly regulated by the central government even when nominally such resources are under the control of respective local governments.

\section{Capabilities for Raising Additional Resources}

Similarly, a relatively richer local economy may be less capable than a less well-off one of raising additional resources because of its limited powers. Unfavorable financial regulation and banking practices may prevent businesses from accessing additional working capital to keep jobs and prevent loss of capital assets under conditions of a decline in production or to investment capital to reorient their production towards new activities. Existing regulations (or lack thereof) may make it impossible for local governments to raise additional financial resources by borrowing from capital markets, establishing PPPs to attract private sector resources, setting up financing mechanisms for other alternative sources of finance, etc. For example, where cities had access to subnational pooled financing vehicles, those proved to be a very valuable source of affordable finance in the face of an increase in public spending. Thus, the city of Karaj (Iran) received funding form the City Bank of Iran owned by 11 metropolitan municipalities to expand its public transport system and increase the number of municipal buses. The Swedish Cooperative Bank Kommuninvest, which serves as a pooled financing agency for Swedish cities, was able to raise SEK 5 billion in a new green bond and $\$ 1.25$ billion in a new benchmark bond in May-June 2020 dramatically improving the access of Swedish municipalities to affordable finance (UNCDF 2020d).

The two above capability areas also cover the capability of local economies and governments to increase access to technical capacities, including in specialized fields, that may be required for minimizing the impact of a crisis situation on service delivery and speedy recovery. This includes application of modern technologies including various digital solutions for local economies. COVID-19 provides many examples of local governments and businesses quickly integrating digital solutions in their business processes to minimize the need for a physical contact and maintain and/or even expand outreach to citizens, customers and suppliers. For instance, Kampala City promoted e-services and online transactions to the general public to continue having access to KCCA services and in support to markets management teams to ensure uninterrupted functioning of food markets under the COVID-19 restrictions. According to the ongoing survey of SMEs in the Least Developed Countries conducted by UNCDF, ICC and a number of other partners (UNCDF 2020b), 43\% of all SMEs resorted to digital solutions to support their sales and other operational aspects (internet, online social media, applications or digital platforms). Yet, in many cases lack of expertise and awareness in communities prevent businesses from switching to more effective digital solutions as the partial data from the SME survey of UNCDF et al. (2020b) shows (Table 2).

TABLE 2

MAJOR OBSTACLES TO ADOPTING DIGITAL SOLUTIONS IN RESPONSE TO COVID-19

\section{ANSWER CHOICES}

Lack of access to expertise

Lack of digital connectivity in the community

Lack of appropriate policies and regulations

Lack of customer awareness

\section{RESPONSES}

$48.57 \%$

$45.71 \%$

$31.43 \%$

$42.86 \%$

This is not to deny the importance of structural facilities. Sure, new flood works will decrease a city's vulnerability to floods and will increase its resilience. But this action may not be possible in the short run and will in any case require mustering necessary resources through reallocation or mobilization within a tight timeline. There is therefore a third set of capabilities that undergirds local resilience in the long run, the capability to identify, envisage and address the existing vulnerabilities. 


\section{Capabilities to Plan and Envisage Resources for Emergency Response}

As Coaffee and Lee (2016:195) emphasize, "resilience is increasingly premised upon accurate risk assessment and the foresighting of future danger". Hence, building resilience should be a forward looking, target driven approach to local development that uses a wide range of measures addressing all elements of local systems. The capacity to anticipate, plan and envisage resources for emergency response is an important dimension of local resilience. It equally concerns public and private economic actors. Not only local governments but also private businesses should incorporate disaster planning (and respective mechanisms) in their operations.

The ongoing COVID-19 crisis has exposed the vulnerability of many global cities, particularly in the South, to breaks in global supply chains, having impacted businesses that rely on imported goods and exportation of goods. According to the ongoing survey of SMEs in the Least Developed Countries conducted by UNCDF (2020), ICC and other partners, about $40 \%$ of SMEs in these countries participate in international trade through exports or imports (Figure 2). This percentage is even higher among larger enterprises and in more developed economies.

FIGURE 2

PERCENTAGE OF SMALL AND MEDIUM ENTERPRISES IN LDCS PARTICIPATING IN INTERNATIONAL TRADE

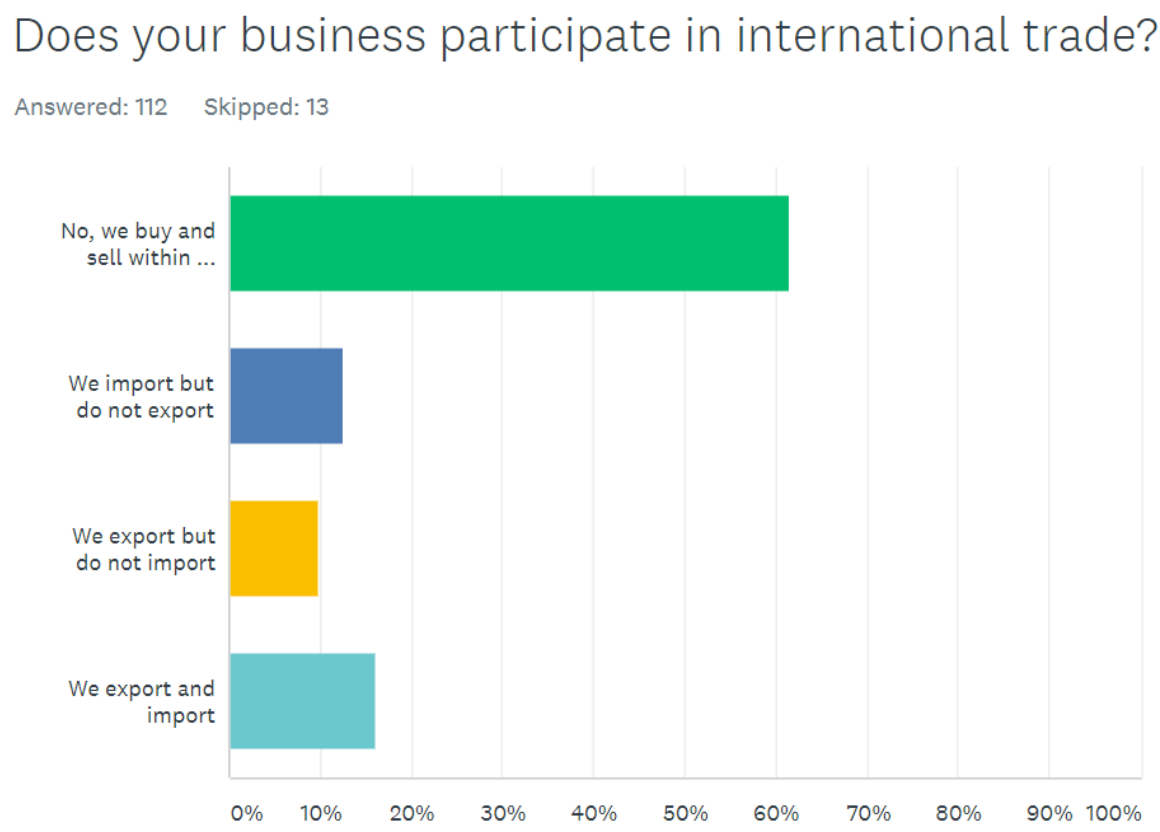

According to the same survey (Table 3), the key challenges for SMEs have been caused by disruptions in international and global supply chains impeding their access to customers, suppliers, spare parts and expertise for operating equipment as well as reduction in the availability and/or price increases for the main inputs. 
TABLE 3

KEY CHALLENGES EXPERIENCES BY SMES IN LDCS DUE TO COVID-19 RESTRICTIONS

\section{ANSWER CHOICES}

Difficulties in accessing customers due to mobility restrictions and/or loss in demand

\section{RESPONSES}

$77.31 \%$

Difficulties in accessing suppliers due to mobility restrictions imposed by government

$46.22 \%$

Difficulties of keeping equipment operating due to lack of imported spare $15.97 \%$ parts/expertise

Reduction in the availability and/or price increases for the main inputs (e.g., supply $\quad 26.89 \%$ chain/logistics disruption, cancelation of public events)

Creation of reserves and some excess capacity, diversification and simplification of supply chains, improving the flexibility and agility of local factor markets (including through a better use of local resources), introduction of digital solutions are just some of the measures local economies can use. Thus, one municipality in Malaysia made enough saving to run the municipality without revenue for 4-5 month and that helped the city go through the lockdown and continue delivering necessary services when its revenues dried up (UNCDF 2020d). As a matter of principle, such measures should be taken together with measures designed to address specific vulnerabilities, for example exposure to natural disasters, such as floods, earthquakes, etc. But unlike those specific measures, resilience building measures cut across all types of emergencies, be they natural or man-made, improving the response capability of local economies rather than their resistance to certain types of shocks.

\section{FIGURE 3 SHOCK AND RECOVERY MODEL}

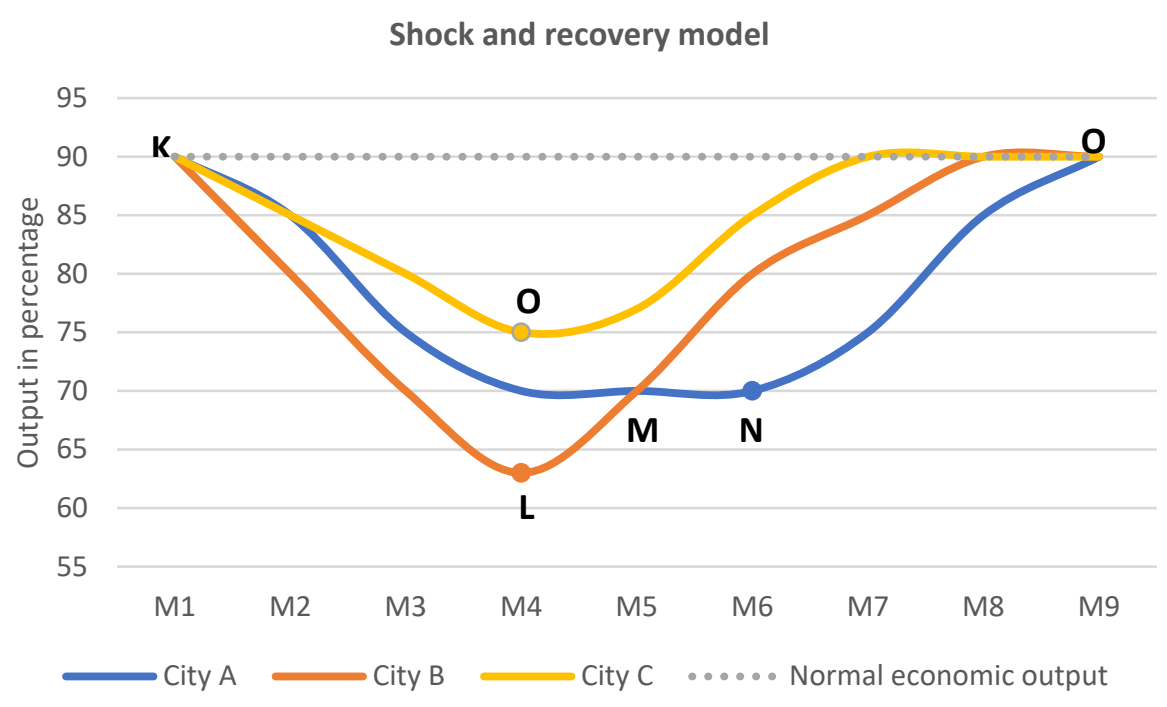

The three capabilities cover the entire emergency cycle including preparation, immediate response and recovery. In other words, the concept of resilience developed here and formulated in the next section is based on an understanding of resilience as a capacity to both absorb shocks and recover from shocks. 
Resilience is thus a product of both capacities. A shock and recovery model shown in Figure 3 explains the interplay between the two capacities. The chart shows three hypothetical cities A, B and C with different shock and recovery curves over a period of 9 months. City A experiences a smaller shock (measured here as a loss in economic output) but a longer recovery period before reaching the pre-crisis employment level. City B, on the other hand, experiences a deeper decline in economic output but recovers faster. Assuming that both cities started at the same level of output, city B demonstrates greater resilience (area K, L, M, O corresponding to the loss of output in this city is less than area $\mathrm{K}, \mathrm{M}, \mathrm{N}, \mathrm{O}$ corresponding to loss of output in city A). Lastly, city $\mathrm{C}$ presents a case with a minimum shock (even smaller than in city A) and a recovery period faster that that of city $B$,

Figure 4 presents the interaction of different capabilities throughout an emergency situation. To some extent, all three capabilities are engaged throughout a crisis but their role differs. Planning and envisaging for resources plays a particularly important role during the pre-crisis period as it allows the city to identify vulnerabilities and bottlenecks and design measures for successful response and recovery. The immediate challenge once the emergence has struck will be to reallocate the existing resources while exploring the opportunities to mobilize additional resources. As the extent and intensity of the crisis becomes clearer, new resources are generated simultaneously with planning and envisaging for the resources required for recovery and better preparedness in the future.

\section{FIGURE 4 \\ RESOURCE MANAGEMENT THROUGHOUT A CRISIS CYCLE}

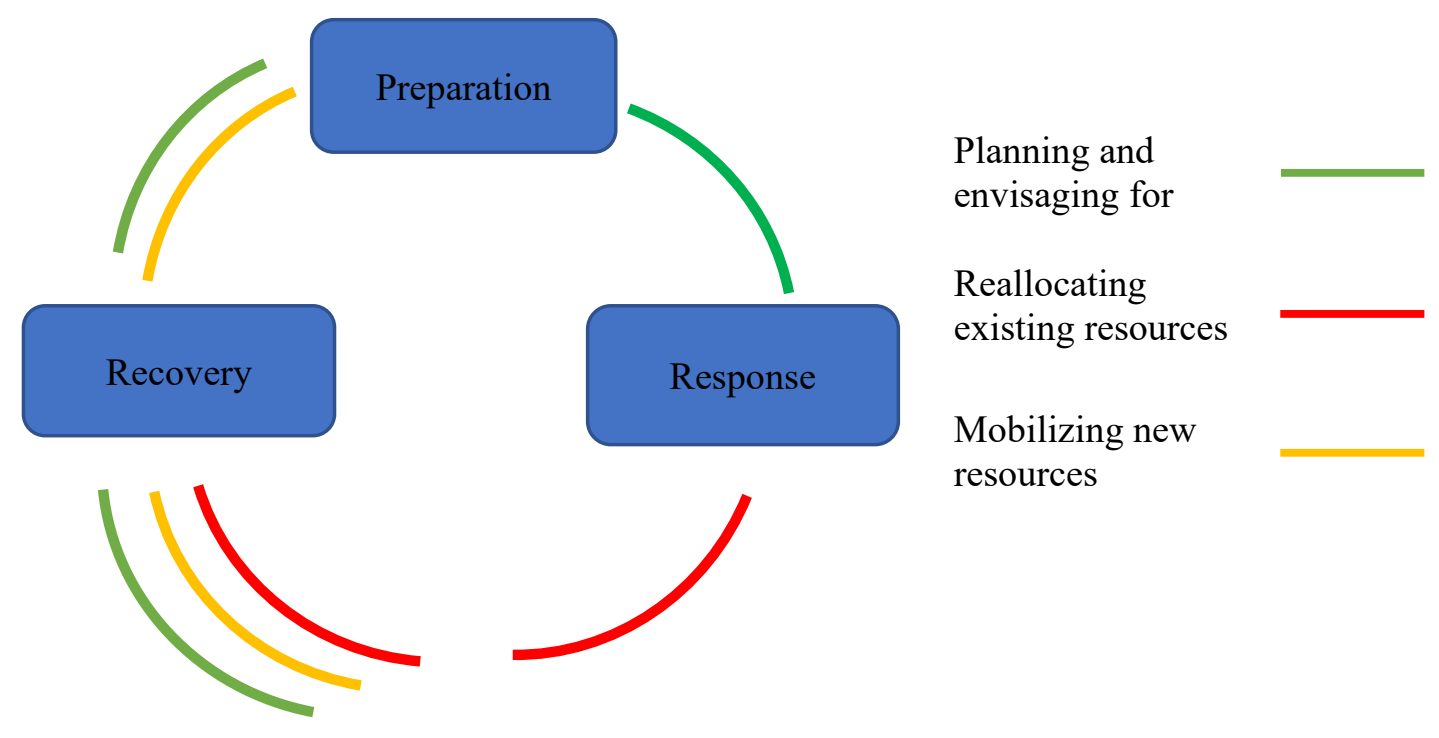

\section{ECONOMIC RESILIENCE IN THE URBAN CONTEXT}

ESCAP (2019) characterizes resilience as an essential tool in urban governance that "comprises a set of strategies that improve policy efficacy, infrastructure implementation, project design, program delivery and urban planning across multiple levels of decision-making and community action".

Attempts have been made in the previous sections to contextualize economic resilience in the local government, particularly urban, setting to try to formulate the answer to the question "Resilience for what?". Meerow et al. (2016) identified 25 definitions of urban resilience in their research, eventually proposing their own definition: "Urban resilience refers to the ability of an urban system - and all its constituent socioecological and socio-technical networks across temporal and spatial scales - to maintain or rapidly return to desired functions in the face of a disturbance, to adapt to change, and to quickly transform systems that limit current or future adaptive capacity." This definition is similar to the more general definitions of 
economic resilience discussed above in its objective (maintain or rapidly return to the desired functions) but brings in a new element-urban system.

Definitions of urban systems abound. Meerow et al. (2016) conceptualize urban systems as complex, adaptive, emergent ecosystems composed of four subsystems - governance networks, networked material and energy flows, urban infrastructure and form, and socioeconomic dynamics - that themselves are multiscalar, networked, and often strongly coupled.

The World Bank (2013) suggests a four-component system of urban resilience--infrastructural, institutional, economic, and social - arguing that this approach can help better identify and address the underlying issues and deepen the city capacity. Unfortunately, this particular publication focuses on infrastructure and social aspects while defining urban economic resilience very narrowly as "a community's economic diversity in such areas as employment, number of businesses, and their ability to function after a disaster". This definition looks inadequate in light of the foregoing discussion and resilience as a dynamic action-oriented concept by all economic actors.

UN-Habitat (2018) understands urban resilience as "the measurable ability of any urban system, with its inhabitants, to maintain continuity through all shocks and stresses, while positively adapting and transforming toward sustainability". This definition also assumes a system-based approach but in addition emphasizes the link between resilience and transformation for sustainability. UN-Habitat (2018) also recognizes both the pro-active and reactive dimensions of resilience: "A resilient city assesses, plans and acts to prepare for and respond to hazards - natural and human-made, sudden and slow-onset, expected and unexpected - in order to protect and enhance people's lives, secure development gains, foster an investible environment, and drive positive change."

UN-Habitat's analytical tool includes eight urban elements of a city system: built environment, supply chain and logistics, basic infrastructure, mobility, municipal public services, social inclusion and protection, economy, and ecology. This analytical tool demonstrates a comprehensive systemic approach but it is sector based and static rather than dynamic. The part of this framework dealing with city economy is based on three pillars:

- Local Economic Structure: Analyses both the stability and potential vulnerabilities of the local economy through measures of diversity, gross product, and employment. Identifies additional structural imbalances in an effort to provide a holistic assessment of market reliability.

- Fiscal Stability and Municipal Finance: Evaluates the fiscal composition and financial capabilities of the local government.

- Market connectivity: Measures the intensity and efficacy of the local economy's connectivity to markets, be they local, regional, national or global.

Arup and Rockefeller Foundation (2015) define resilience as the capacity of cities to function, so that the people living and working in cities - particularly the poor and vulnerable - survive and thrive no matter what stresses or shocks they encounter. Their Cities Resilience Framework situates resilience in a system that includes four categories: the health and wellbeing of individuals (people); urban systems and services (place); economy and society (organisation); and, finally, leadership and strategy (knowledge).

The concept of capacity or capability does appear in many definitions although overall, the analysis remains somewhat static and built around certain structural characteristics rather than actions. But an important feature of these definitions is their systems-based approach, however different elements of the system are defined. It is also their common emphasis on the systemic nature of the urban dimension, mutual interdependencies and interconnectedness in an ecosystem or combination of ecosystems. In this latter respect, a number of authors (Martin et al. 2015) stress the importance of national policies and regulations for local economic resilience.

To bring together the two aspects - economy and locality — in a cohesive approach to urban economic resilience, urban economy was treated as not just a "small" economy confined in the boundaries of a city but as a more or less autonomous but closely connected part of national economy that has a specific objective of local economic development, i.e. "creating and utilizing physical, human, financial, and social assets to generate improved and broadly shared economic well-being and quality of life for a community or region" (Seidman 2005). 
Recognizing the dynamic nature of resilience in general, this concept note suggests the following definition of urban economic resilience.

Urban economic resilience is the capacity and related capabilities of urban communities to plan for, anticipate negative shocks, including long-term stresses, to their economies, reallocate and mobilize resources to withstand those shocks, recover from the shocks, and rebuild at least to pre-crisis levels as soon as possible, while placing their economies on the path to sustainable economic growth and simultaneously strengthening their capacity to deal with any future shocks.

This definition is action- and agency-oriented putting urban communities in the driver's seat rather than speaking about faceless "systems". It also specifies the resource management actions that may be taken to improve urban resilience. Also, this definition indicates the focus of the proposed actions: economic systems and factor markets. In addition, it incorporates both the shock absorption and recovery capacities of a city. Lastly, it identifies the final objective of resilience actions, with respect to both positive and negative shocks.

\section{URBAN ECONOMIC RESILIENCE: KEY COMPONENTS AND INDICATORS}

Since the proposed resilience actions refer to a number of economic systems and markets, there is a need to identify those systems and markets to proceed to identification of resilience indicators in a more orderly and logical manner. The proposed conceptual model of urban resilience incorporates five components: business environment; governance arrangements; labour market conditions, financial arrangements and basic services and connectivity.

The former two refer to systems and describe, respectively, the conditions and structure of business operation in a locality (both public and private) and economic governance arrangements. The next two refer to two factor markets in a locality: labour and capital. Furthermore, recognizing the link between vulnerability and resilience at the causality level, this concept distinguishes between causal variables and indicator variables. The actual reallocation and mobilization of resources takes place in factor markets but business and governance arrangements define "the rules of the game" and set the institutional constraints for these markets (North 1990). The last component emerged during our consultations with the partner cities in the context of the UN joint project on urban economic recovery and resilience. This component reflects the reality on the ground that the four components of the city economy (representing the factors of production operating within specific governance arrangements) cannot function without some basic infrastructure in place (e.g., energy, water, waste management, etc.) and require adequate mobility and connectivity (physical and digital) for their efficient operation.

Considering that urban resilience presents an unobserved latent variable, the concept distinguishes between causal and effect indicators. This approach allows consideration of multiple causes and multiple indicators of the phenomenon to be measured, i.e. it explicitly considers multiple causes leading to urban economic resilience as well as the multiple effects of resilience over time.

Causal indicators of economic resilience would be closely related to the causes of vulnerability. For example, industry high concentration (or low diversity) implies higher vulnerability because it limits the capability to shift resources (labour and capital) across sectors of local economy. A more diversified local economy will certainly improve resilience but this is a strategic challenge (which may not even be feasible because of the locality characteristics). What would matter in the short run, is the existing institutional and financial arrangements to allow economy to quickly switch over to other economic activities, to different suppliers and customers, access working capital to maintain a certain level of production, etc.

The identified causal and indicator variables are arranged in a $3 \times 5$ matrix along two dimensions: resilience capabilities and economic resilience components. Figure 5 presents a conceptual framework of urban economic resilience with the select causal indicators. Of course, there are no impenetrable borders 
between different components because they are linked into a local economy ecosystem. The impact of these indicators on urban economic resilience is explained below.

\section{FIGURE 5 CONCEPTUAL FRAMEWORK OF URBAN ECONOMIC RESILIENCE}

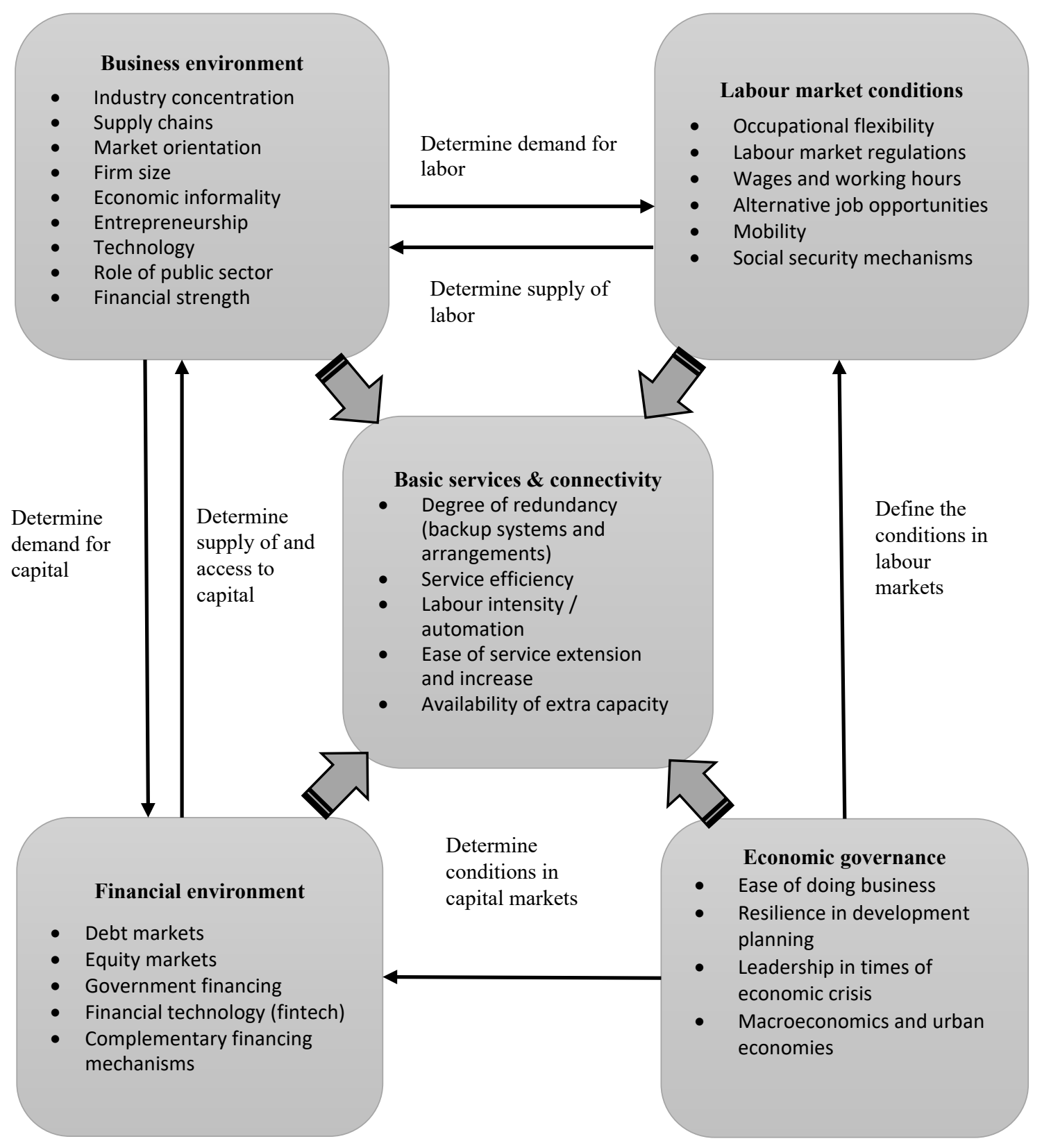

Source: UNCDF (2020d)

\section{Impact of Causal Indicators on Urban Economic Resilience}

This subsection attempts to define the causal indicators and their relationship to the variable of interest, i.e., urban economic resilience. Each casual variable is described and its relationship (positive or negative) with resilience is explained. The analysis is structured around the five components of an urban economic ecosystem and does not pretend to being exhaustive. Whereas the analysis attempts to be as general as possible, the theoretically predicted relationships between the causal indicators and urban economic 
resilience may differ for economies with different structural characteristics and levels of development. This concerns, for example, such issues as the role of the firm size, informal sector, and women participation in the labour force to name just a few (for a comprehensive discussion of how various causal variables are interpreted in different resilience assessment systems, see chapter 5 of Coaffee and Lee 2016).

\section{Business Arrangements}

- Sector concentration. Sector concentration refers to the degree of local economy's diversification. Mono-sector and highly concentrated economies are by definition more vulnerable to shocks because the possibilities of reallocating resources across other sectors are limited or nonexistent. Hence, the higher the sector concentration, the lower resilience due to limited opportunities for resource reallocation.

- Extension/complexity of supply chains. The more extended and complex are the supply chains, the higher the probability that they will be disrupted hence leading to lower resilience. The higher is the local content, the more resilient is the economy.

- Market orientation. The same is true for market orientation, the more locally oriented a market is in terms of customers/users, the less is the probability of its disruption, which makes local economy more resilient.

- Firm size and status (formal/informal). The smaller the firms, the less resilient they are, decreasing the overall economic resilience of the locality. The share of the informal sector produces a mixed impact: the higher this share, the higher is the impact of the crisis. Informal enterprises are likely to be the first to go out of business during a crisis (UN-Habitat et al. 2020). However, informal enterprises are also more likely to recover and get back into business faster than formal enterprises although their low productivity limits their impact on economic recovery (La Porta and Shleifer 2014). Still, a large informal sector is normally associated with lower resilience (Coaffee and Lee 2016).

- Entrepreneurship and innovativeness. The higher these two characteristics, the higher is resilience implying faster reallocation of resources, entry into new businesses and minimizing the impact through innovative technological and business solutions.

- Access to technologies including digital. As discussed in the previous sections, on average businesses that apply cost-saving and productivity-enhancing technologies, including different digital solutions, have done better during COVID-19 than other businesses. On average, such businesses have seen 20\% less in revenues losses and 30\% less in layoffs (UNCDF 2020c). Hence, the higher the technological capacity (access to and use of advanced technologies), the better the city resilience.

- Share of the public sector. The higher is the share of the public sector in a locality, the more resilient it is. The public sector is known for its efforts to ringfence public employment even under adverse conditions, thus contributing to continued performance of economic functions and basic services and maintaining the local purchasing power. Furthermore, the public sector may have access to financial and real assets that may not be easily accessible (or at least accessible in the short run) to the private sector. Hence, the role of public sector (determined to some extent by its share but also by its strategic positioning as will be discussed further) for crisis management cannot be overestimated (Mazzucato and Quaggiotto 2020).

- Financial strength and capacity to raise funds. The financial muscle (the level of capitalization, profitability) is a good indicator of the ability to attract additional capital. The less indebted public and private sectors are and the more their financial depth (capitalization), the more financial resources they can muster to improve economic resilience.

\section{Labour Market Conditions}

- Occupational flexibility of workers. The more skilled the local labour force is and more ready to move to a different occupation in response the changing demand in the labour market, the higher 
is urban economic flexibility. High specialization may inhibit workers' transition to other occupational opportunities.

- Labour market restrictions. Using flexible employment arrangements (e.g., part-time employment, special wage arrangements, different working conditions, etc.) may become critical for maintaining critical economic activities and public services. The more flexibility labour regulations allow, the higher local economic resilience.

- Wages and hours flexibility. The changing conditions in the labour market may require unusual employment conditions in terms of wages and hours. This also may include work-sharing social arrangements when the reduced amount of work is divided between the same number of workers to ensure a continuous although reduced income to the number of workers a company used to have without a layoff. The more willing the local labour force and employers are to accept such conditions, the higher local economic resilience.

- Alternative job opportunities. This refers to the job richness of the local economy and its capacity to offer alternative job opportunities to the workers whose jobs may have been affected by a crisis. It a common occurrence, particularly in developing economies, when workers combine more than one job, allowing them to maximize their effort in the less endangered occupations to mitigate the loss of another job. The more job opportunities the local economy can offer (or create at a short notice), the higher local economic resilience.

- Labor mobility. In the context of urban economic resilience, mobility refers to labour force mobility between the urban area and the adjoining peri-urban/rural areas. If the mobility is high, it helps reallocation of labour resources between different areas and sectors and hence improves local economic resilience. However, mobility (even with the neighboring areas) may be severely affected due to containment measures and lockdowns as the experience of COVID-19 shows.

- Attachment to labour markets refers to the labour force position vis-à-vis the existing labour markets. Employment rates as well as some other dimensions such as the availability and willingness to engage in labour markets. The employment statistics (including, for example, the gender composition of the labour force) may not be particularly relevant in the context of urban resilience because it sends mixed signals. For instance, a higher unemployment rate may indicate the existence of a reserve labour force that can be quickly deployed in an emergency situation. Furthermore, high unemployment figures may be hiding informal employment or employment in subsistence agriculture. In this sense, the share of persons available and willing to engage in labour markets is a more meaningful indicator of access to additional labour resources. A higher share of such persons implies a higher local economic resilience.

- Social security mechanisms. These mechanisms play a particularly important role during a health crisis with a massive job loss and drop in personal incomes. Social security mechanisms are designed to provide protection to workers going through a health and economic crisis. It helps maintain a certain level of aggregate demand and prevents immiseration of workers in difficult situation and their households. The more developed such mechanisms (even when they need to be funded by the government rather than by employers as has been the case during the current crisis), the better is local economic resilience.

\section{Financial Arrangements}

- Debt market conditions define access to additional debt finance for the public and private sector. The cost of debt finance, financial institutions' risk appetite as well as credit rationing (i.e., systematic exclusion of certain business sectors from debt markets) (Stiglitz and Weiss 1981) may restrict access to capital at exactly the time when it is most needed. The lower is the private sector credit as a share of total bank assets, particularly credit to small and medium enterprises in the real economy sector that make up the bulk of any local economy, the lower local economic resilience. 
- The same is true for equity market conditions. The more restricted is the equity offering in terms of its size and type (impact and venture finance, for example), the more difficult it is to raise additional equity finance, which weakens local economic resilience.

- Public financial and nonfinancial support mechanisms to facilitate access to capital. In a situation when the financial sector itself may be hit by a crisis, resulting in reduced supply of finance, the role of the public sector in keeping the wheels of economy oiled by providing liquidity and capital becomes very important. The more is the capacity of the public sector to extend financial support (grants, loans, guarantees) and nonfinancial support (for example, project development and structuring assistance, access to technologies, training, etc.) that may help private firms to unlock financial markets, the more resilient is the urban economy.

- Digital banking and digital finance. Access to finance has an operational aspect. In almost all countries the financial sector has been designated as an essential service as remained open through the lockdown. However, many local branches got closed (or even never existed in the first place), and the movement restrictions have made it very difficult to access financial services physically. In this situation, financial institutions with well-developed digital services fared much better as their clients continued to enjoy an interrupted access to their savings or credit. Similarly, the countries where mobile money transfers are widespread not only between persons but also between businesses (particularly informal and smaller ones) have not experienced any interruptions in financial transactions. The COVID-19 crisis is boosting mobile money globally, with such countries as Rwanda recording a five-fold increase in transactions during the lockdown period. Hence, digital technologies contribute to better resilience.

- Alternative finance mechanisms cover a broad range of institutional arrangements and structures (financing vehicles, funding mechanisms, etc.) that facilitate access to capital from alternative sources. Local governments may have local economic development corporations (funds) or municipal banks, local government loan boards and other forms of subnational pooled financing mechanisms that may provide additional liquidity to the urban government and private sector entities. Similarly, it involves regulations and structures for public private partnerships in various forms (from loosely defined joint ventures to classical PPPs) that allow the public and private sector to bring together their resources and minimize risks (if the partnership is properly structured and implemented). Lastly, alternative finance mechanisms include platforms and structures for raising internal and external donations, philanthropic and similar types of finance. The more developed the alternative finance system is, the more resilient is the local economy because this type of finance helps diversify financial sources.

\section{Economic Governance Arrangements}

- Ease of doing business/intensity of regulation. Ease of doing business becomes particularly important when economic actors need to readjust quickly to the new conditions engendered by a crisis, such as changes in the factor markets, supply and demand disbalances, etc. Firms should be able to switch to new types of production (if possible), adjust labour conditions (for example, by keeping workers onsite 24 hours) expeditiously and without much red tape. In some countries, companies were being prevented from starting new production (such as masks, for example), despite having the necessary, because this activity was not expressly mentioned in their registration papers. The easier is the business (re)registration and licensing procedures, the less time it takes, the more resilient is the local economy.

- Resilience integration in local government economic policies, strategies, and plans. This is a critical condition for helping local economies to absorb the shock and recover faster. Do local government economic policies, strategies and plans identify the existing vulnerabilities and specify realistic and feasible measures to address them in the long and medium run as well as the short-term contingency measures? Are there institutional platforms and mechanisms to engage all relevant partners in the discussions about local resilience strategies? Do annual plans and budgets have contingency 
provisions in case of emergency? Are there strategic contingency reserves, such as local food reserves, for example? If these and other similar issues are reflected in local economic policies, strategies and plans and implemented systematically, urban economic resilience is higher.

- Ease of public decision-making at the local level (including spending). This is the proverbial "last but not least". Essentially, at stake is the discretion of local decision-making process. It has several aspects but two stand out for the purposes of this discussion: administrative and financial. The criticality of the administrative aspect has already been discussed in the context of economic and business regulation. Can local governments register or re-register businesses? Can local governments license businesses? Can they offer relief packages and exempt businesses from certain charges and fees? Can local governments take on their own decisions on mobilization and/or reallocation of local resources (for example, labour mobilization for public works)? On the financial side, the important questions concern the discretionary powers to take budget decisions. This is of course determined by the financial position of the local government, its total resource envelope as well as the size of its discretionary fiscal space (in terms of own source revenues and unconditional grants). The greater are the local discretionary powers, the faster and the more targeted resource reallocation or mobilization it can achieve and the better is therefore local economic resilience.

\section{Basic Services and Connectivity}

- Degree of redundancy (backup systems and arrangements). This is designed to measure the resilience of basic services and connectivity under conditions when some elements of the system may be rendered inoperative under health and economic stress. For example, the COVID-19 situation has revealed the challenge of low redundancy of healthcare systems in many locations when access to vital equipment and personnel was severely constrained. A higher degree of redundancy has a positive effect on urban resilience.

- Service efficiency. Efficient services that cost cheaper per unit and consumer less inputs are usually more resilient to the impact of a crisis, particularly when requirements for public spending may increase without a matching increase in revenues (as has been the case during the ongoing pandemic).

- Labour intensity/automation. As a large number of employees may be affected by lockdown restrictions, lack of adequate transportation or health issues, the importance of continued service delivery with minimum direct human involvement becomes more critical. Cities that rely on automated systems for traffic management, contact tracking, digital solutions for public awareness, distribution of social assistance, vaccination and other essential services have demonstrated higher resilience and better outcomes during the ongoing pandemic. For example, the city of Lima applied a city-wide geospatial analysis to identify availability of public and private infrastructure, population density, traffic intensity and other local characteristics in order to maximize the impact of specific measures in particular locations (UNCDF 2020d).

- Ease of service extension and increase. COVID-19 has demonstrated the criticality of a quick extension of essential public services to the areas where such services are lacking to contain the spread of the infection and minimize the social and economic impact of COVID-19. The city of Kampala in Uganda developed and implemented a series of action plans to detail a complex of priority measures required in each informal settlement, including, for example, construction of additional water points, re-arrangement and regulation of informal markets, improvements of communal latrines and sewage systems and so on (UNCDF 2020d). The ease of service extension depends on the organization of the service, required inputs, technologies and designs, and other factors.

- Availability of extra capacity. This variable is related to redundancy but is different in that while redundancy ensures uninterrupted service delivery at the same level, extra capacity allows quick enhancement of the service using reserve facilities, stockpiled materials and/or trained staff who 
can be easily mobilized in case of need. Considerations of extra capacity (healthcare is an obvious example) should take place during the planning phase and be integrated into local crisis management plans and budgets.

\section{Key Effect Indicators}

Effect indicators are those that reflect changes in the unobserved variable of interest (i.e., urban economic resilience). Four indicators have been identified as having potentially significant correlation with urban economic resilience as explained below.

- Per capita gross city product growth. Gross city product growth is determined by many factors, quite a few of them structural and relatively immutable in the short to medium run. However, in a resilient economy that has a good shock absorptive capacity and a recovery capacity that allows a speedy recovery, the growth rates should be stable without significant fluctuations, ceteris paribus.

- Labor force participation rate. What has been said about gross city product growth is also true for labor force participation rate growth. Whatever are the determinants, there should be a positive correlation between stable participation rates and a resilient economy. The proposed indicator is people over 15 economically active as a percentage of total population.

The above two measures commonly appear as indicator variables in a number of resilience and sustainability assessments (Coaffee and Lee 2016). The next two variable appear less often and merit more explanation.

- Inequality rate. The association between inequality and economic development has been debated since Simon Kuznets hypothesized an eponymous curve in the 1950s (Kuznets 1955). The contemporary consensus among economists is that higher levels of inequality undermine development. This is indeed the guiding principle of the 2030 Agenda for Sustainable Development with its central promise to 'leave no one behind'. The UN Framework for the immediate socio-economic response to COVID-19 (2020) also points to a link between the COVID-19 crisis and growing inequalities. ${ }^{2}$ It is clear from the earlier discussion that a resilient economic system should be able to not only quickly return to a state of equilibrium quo ante but ideally to achieve a higher equilibrium point than before ("rebuild better"). Hence, a resilient economy should be characterized, at least in the short and medium run, by stable (preferably even declining) inequality rates. The specific inequality metric suggested for measuring urban economic resilience is the Palma ratio, which is the ratio of the richest $10 \%$ of the population's share of the total income divided by the poorest 40\%'s share. Although the Gini coefficient is more common, it is by construction oversensitive to the middle, and less sensitive to the tails underestimating inequality for the poorest and the richest (Cobham et al. 2015).

- Change in own source revenue. Domestic revenues in general and local own source revenues in particular have been hit hard by the COVID-19 crisis as discussed in the previous sections. The composition of the total budget envelope differs for local governments in different countries. Cities in more economically developed countries with a higher degree of fiscal decentralization rely more on own source revenues; smaller cities and towns with less revenue potential and in less developed countries with more central government control reply on central government transfers (UNCDF 2020a). There is no uniform own source revenue rate that could be correlated with a resilient economy. While there is not much a city can do about central government transfers if they decline, it is obvious that a resilient economy should not record significant own source revenue fluctuations in the medium and long run (in the short run such fluctuations are inevitable under conditions similar to COVID-19). Furthermore, the change in own source revenues should be proportionate to the GCP growth and population growth.

- Circular material use rate. Given the imperative to recover not only better but also greener, introducing an indicator of economic circularity appears very appropriate. It is generally 
accepted that a resilient economy is also a circular economy, which "aims at increasing the amount of material recovered and fed back into the economy, therefore reducing the generation of waste and limiting the extraction of primary raw materials" (Eurostat 2018). The circular material use rate measures the contribution of recycled materials to overall materials demand.

It goes without saying that the first three indicator variables should be gender disaggregated to establish their gender dimension. Obviously, a more resilient economy is expected to have higher levels of gender equality.

\section{Key Indicators for Urban Economic Resilience}

The above discussion provides enough ground for identifying some key indicator variables for urban economic resilience in the form of a $3 \times 4$ matrix (Table 4). The matrix operationalizes the causal variables discussed in the earlier sections through a number of indicators. Some indicators are defined as indices. An attempt has been made to use the existing indices rather than suggest new ones. However, in practice a number of such indices exist only at the national level and collecting city-level data may require significant efforts which may not be economically justified. In such cases simple proxy indicators need to be identified where possible. All indicators should be gender-disaggregated as much as possible. 


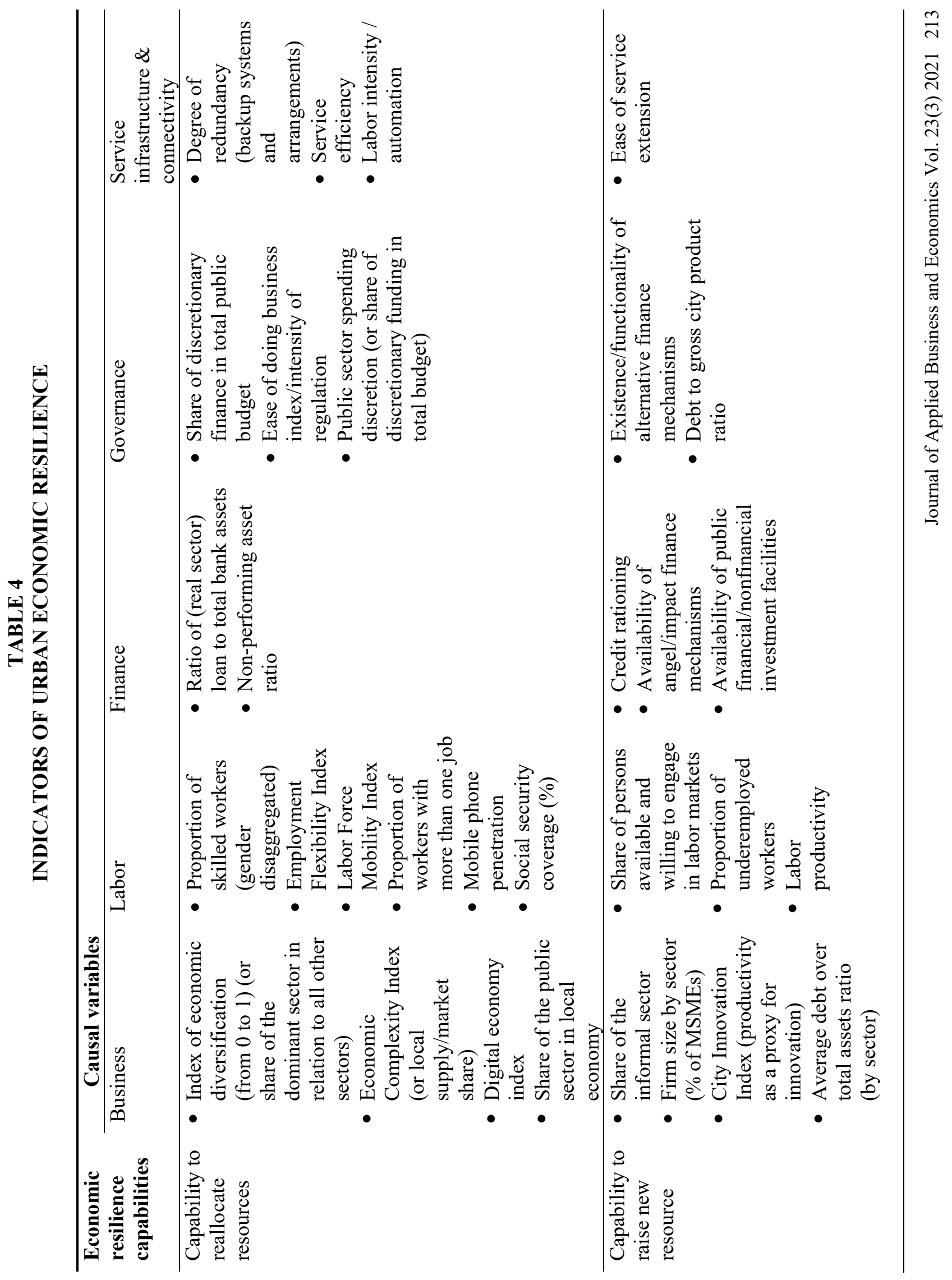




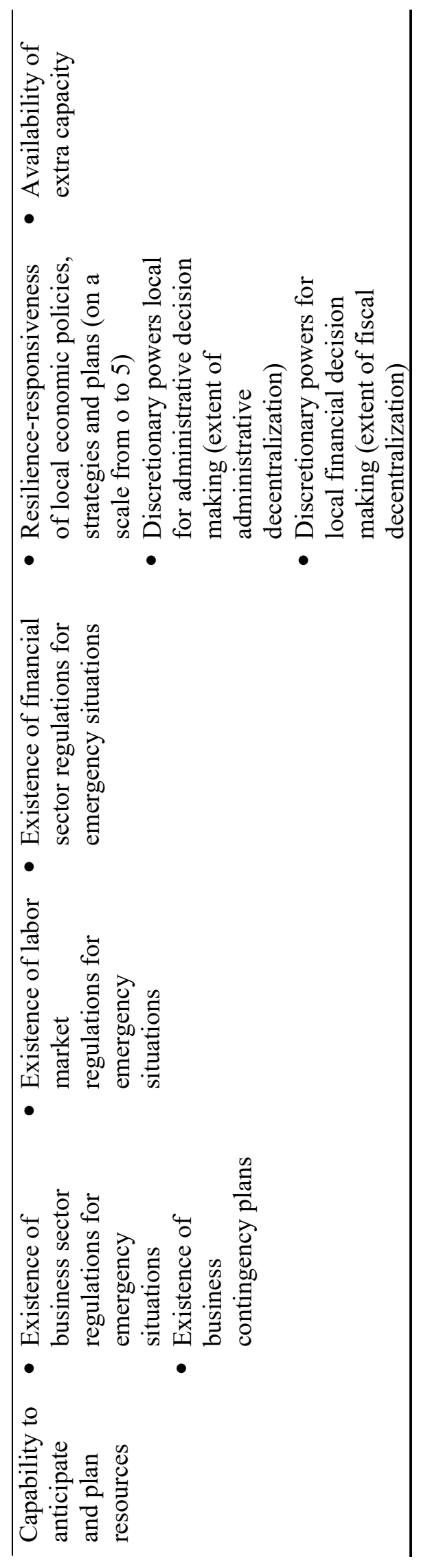

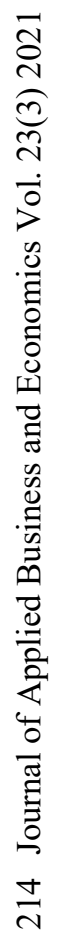




\section{CONCLUSION}

This paper presents a conceptualization of urban economic resilience for further discussion of both the methodology involved and the specific causal and effect indicators. To recap, the methodology involved four steps:

- Identification of key cross-cutting policy actions that underlie urban economic resilience to inform policies and strategies at the city level.

- Identification of five components of a system of urban resilience.

- Identification of causal and effect indicators to define urban resilience in each of the four components.

- Relating indicator variables to cross-cutting policy actions in a 3 x 5 matrix.

The potential advantage of the proposed conceptualization involves a relatively small number of indicator variables to minimize data collection efforts (although some indicators are in fact composite indices and arriving at index values will involve additional work). It is also important to establish what data is available and whether some indicators will have to be replaced with more available proxies.

The other advantage is that the concept presented in this paper may be used to perform multiple regression analysis to measure dependence of urban economic resilience on a set of observable causal indicators. The extent of the economic shock in individual cities is known by now (although this may not be the final tally as some countries and cities reintroduce lockdown measures) and the recovery period may also be known by the time the concept is agreed and starts to be applied (or at least the degree of recovery since the lifting of lockdown measures). These can be used as indicator variables to test the model and establish its applicability. If enough city-level data are available, this approach will allow identification of the variables that are significantly correlated with urban economic resilience, be they from the domain of economic governance or local business environment or other components of urban economic resilience. Thus, cities will be equipped with a better understanding of what determines resilience to a greater extent and where they should concentrate their action as a matter of priority (although one size fits all rarely works and a great degree of customization will be required in any case).

Yet another practical application of the concept is to serve as a foundation for an urban resilience diagnostic system. Such a system will analyze the city performance against different indicators presented in this paper by assigning certain performance scores based on the performance of the best performing cities who have systematically demonstrated high levels of resistance. Cities will thus be able to self-assess their performance to identify relatively weak areas of performance and then develop local economic resilience building plans as part of broader recovery strategies. The Joint UN Project "Urban economic and financial recovery and resilience building in the time of COVID-19" explained at the beginning of this paper has already developed a diagnostic and planning tool for urban economic recovery and resilience based on the concept of urban resilience presented here. The tool is currently being applied in 16 partner cities around the world.

If the global financial crisis of 2008-09 is any guide, we can and should expect varying recovery trajectories. For example, in Europe the crisis hit both advanced and emerging economies (IMF 2017). On average, output contracted about $71 / 2$ percent (unweighted) in the 35 European countries that experienced a recession in 2008-09 (comparable to the latest IMF forecasts for COVID-19). But recovery speeds varied. Central European countries and South East Europe have resumed their relatively more robust growth pattern, though at more subdued levels than before the crisis. Growth in non-euro area advanced European countries has picked up sooner than in advanced euro area countries, some of which experienced a second recession in 2011-12. There is no doubt that urban economic resilience (albeit mitigated by the national trends) will play a decisive role in shaping the COVID-19 recovery paths in cities around the world. 


\section{ENDNOTES}

1. The paper is based on a Background Note for the joint UN Project "Urban economic and financial recovery and resilience building in the time of COVID-19". The project is a joint effort of a number of UN agencies and subsidiary bodies to operationalize the relevant provisions of the UN Framework for the immediate socioeconomic response to COVID-19 (2020). It is implemented by the UN Economic Commission for Europe (UNECE), UN Economic Commission for Africa (UNECA), UN Economic and Social Commission for Western Asia (UNESCWA), UN Economic and Social Commission for Asia and the Pacific (UNESCAP) and the UN Economic Commission for Latin America and the Caribbean (UNECLAC) with the participation of UN-Habitat and the UN Capital Development Fund (UNCDF). The joint UN project has a specific focus on economic and financial recovery in the urban context and is implemented in 16 partner cities around the world: Albania (Tirana), Cameroon (Yaoundé), Ecuador (Guayaquil), Egypt (Alexandria), Fiji (Suva), Ghana (Accra), India (Pune), Kuwait (Kuwait), Kyrgyzstan (Bishkek), Lebanon (Beirut), Malaysia (Subang Jaya), Perú (Lima), República Dominicana (Santo Domingo), Ukraine (Kharkiv), Viet Nam (Hoi An), Zimbabwe (Harare).

2. Economic theory suggests that the COVID-19 pandemic will generate rising inequality. The crisis has intensified the already existing trend of automation and transition to more capital-intensive businesses as machines appear more attractive to employers, particularly in the contracting sectors that use relatively more unskilled labor. The return to capital will thus increase. And, because low-income people must spend a larger share of their income on basic goods than those at the top, any automation-driven increase in inequality will be contractionary (Stiglitz 2020).

\section{REFERENCES}

Auerbach, A., Gale, B., Lutz, B., \& Sheiner, L. (2020). Fiscal Effects of COVID-19. Brookings Papers on Economic Activities. The Brookings Institution. Retrieved from https://www.brookings.edu/wpcontent/uploads/2020/09/Auerbach-et-al-conference-draft.pdf

Brada, J., Gajewski, P., \& Kutan, A.M. (2021). Economic resiliency and recovery, lessons from the financial crisis for the COVID-19 pandemic: A regional perspective from central and Eastern Europe. International Review of Financial Analysis. https://doi.org/10.1016/j.irfa.2021.101658

Briguglio, L., Cordina, C., Farrugia, N., \& Vella, S. (2008). Economic Vulnerability and Resilience: Concepts and Measurements. UNU-WIDER Research Paper No. 2008/55.

Chmutina, K., Llzarralde, G., Dainty, A., \& Bosher, L. (2016). Unpacking resilience policy discourse. Cities, 58, 70-79.

City of Barcelona. (2020). Barcelona Never Stops. Action Plan. Retrieved from https://www.barcelona.cat/reactivacioeconomica/en/action-plan

Coaffee, J., \& Lee, P. (2016). Urban Resilience (Planning, Environment, Cities). London: Macmillan Education UK.

Coaffee, J., \& Lee, P. (2016). Urban Resilience: Planning for Risk, Crisis and Uncertainty. London: Palgrave.

Cobham, A., Schlogl, A., \& Sumner, A. (2015). Inequality and the Tails: The Palma Proposition and Ratio Revisited. DESA Working Paper No. 143 ST/ESA/2015/DWP/143. New York: UNDESA.

Davoudi, S. (2012). Resilience: A bridging concept or a dead end? Planning Theory \& Practice, 13(2), 299-333.

Di Pietro, F., Lecca, F., \& Salotti, S. (2020). Regional economic resilience in the European Union: A numerical general equilibrium analysis. Spatial Economic Analysis. DOI:

$10.1080 / 17421772.2020 .1846768$

Earthquakes and Megacities Initiative. (2015). A Guide to Measuring Urban Risk Resilience: Principles, Tools and Practice of Urban Indicators.

ESCAP. (2019). The Future of Asian and Pacific Cities. Transformative Pathways towards Sustainable Urban Development. Bangkok: United Nations. 
European Commission. (2020). Communication from the Commission to the European Parliament, the European Council, the Council, the European Economic and Social Committee and the Committee of the Regions. Europe's moment: Repair and Prepare for the Next Generation. Retrieved from https://eur-lex.europa.eu/legalcontent/EN/TXT/PDF/?uri=CELEX:52020DC0456\&from=EN.

Eurostat. (2018). Circular material use rate. Luxembourg: Publications Office of the European Union.

Fayers, P., \& Hand, D. (2002). Causal variables, indicator variables and measurement scales: An example from quality of life. J. R. Statist. Soc., 165(2), 233-261.

Gans, J. (2020). Economics in the Age of COVID-19. Cambridge, MA: MIT Press.

Gitz, V., \& Meybeck, A. (2012). Risks, vulnerabilities and resilience in a context of climate change. In Building Resilience for Adaptation to Climate Change in the Agriculture Sector. Rome: FAO.

Gong, H., Hassink, R., Tan, J., \& Huang, D. (2020). Regional Resilience in Times of a Pandemic Crisis: The Case of Covid-19 in China. Tijdschrift voor Economische en Sociale Geografie, 111(3), 497512. DOI:10.1111/tesg.12447

ICLEI. (2011). Financing the Resilient City: A demand driven approach to development, disaster risk reduction and climate adaptation. An ICLEI White Paper, ICLEI Global Report.

International Monetary Fund. (2017). Credit Growth and Economic Recovery in Europe After the Global Financial Crisis. WP/17/256. Washington, DC: IMF.

International Monetary Fund. (2020, April). Fiscal Monitor. Retrieved from https://www.imf.org/en/Publications/FM/Issues/2020/04/17/Fiscal-Monitor-April-2020-Chapter1-Policies-to-Support-People-During-the-COVID-19-Pandemic-49278

IPCC. (2001). Climate Change 2001: Impacts, Adaptation, and Vulnerability. Intergovernmental Panel on Climate Change. Cambridge, UK: Change.

IPCC. (2012). Managing the Risks of Extreme Events and Disasters to Advance Climate Change Adaptation. Intergovernmental Panel on Climate Change. Cambridge, UK: Change.

Kuznets, S. (1955). Economic growth and income inequality. The American Economic Review, 45(1), 128.

La Porta, R., \& Shleifer, A. (2014). Informality and Development. Journal of Economic Perspectives, $28(3), 109-126$.

Martin, R., Sunleyb, P., \& Tylerc, P. (2015). Local growth evolutions: Recession, resilience and recovery. Cambridge Journal of Regions, Economy and Society, 8, 141-148.

Mazzucato, M., \& Quaggiotto, G. (2020). The Big Failure of Small Government. Project Syndicate. Retrieved from https:/www.project-syndicate.org/commentary/small-governments-big-failurecovid19-by-mariana-mazzucato-and-giulio-quaggiotto-2020-05?barrier=accesspaylog

Meerow, S., Newell, J.P., \& Stults, M. (2016). Defining urban resilience: A review. Landscape and Urban Planning, 147, 38-49.

North, D. (1990). Institutions, Institutional Change and Economic Performance. Cambridge, UK: Cambridge University Press.

Noy, I., \& Yonson, R. (2018). Economic Vulnerability and Resilience to Natural Hazards: A Survey of Concepts and Measurements. Sustainability, 10, 2850.

Noy, I., Doan, N., Ferrarini, B., \& Park, D. (2020). Measuring the Economic Risk of Covid-19. CESifo Working Paper, No. 8373. Munich: Center for Economic Studies and Ifo Institute (CESifo).

O’Hare, P., \& White, I. (2013). Deconstructing Resilience: Lessons from Planning Practice. Planning Practice \& Research, 28(3), 275-279.

Paulais, T. (2009). Local Governments and the Financial Crisis: An Analysis. Washington, D.C.: TheCities Alliance.

Proag, V. (2014). The Concept of Vulnerability and Resilience. Procedia Economics and Finance, 18. Doi:10.1016/S2212-5671(14)00952-6

Régibeau, P., \& Rockett, K. (2013). Economic Analysis of Resilience: A Framework for Local Policy Response Based on New Case Studies. Journal of Innovation Economics, (11), 107-147. 
Rockefeller Foundation. (2014). City Resilience Framework (New York and London: The Rockefeller Foundation: With Ove Arup \& Partners International). Retrieved from https://www.rockefellerfoundation.org/report/city-resilience-framework/

Schwab, K., \& Malleret, T. (2020). COVID-19: The Great Reset. Geneva: Forum Publishing.

Seidman, K. (2015). Economic Development Finance. Thousand Oaks, CA: Sage Publications.

Shamsuddin, S. (2020). Resilience resistance: The challenges and implications of urban resilience implementation. Cities, 103.

Stiglitz, J.E. (2020). Priorities for the COVID-19 Economy. Retrieved from https://www.socialeurope.eu/priorities-for-the-covid-19-economy

Stiglitz, J.E., \& Weiss, A. (1981). Credit Rationing in Markets with Imperfect Information. The American Economic Review, 71(3), 393-410.

Stiglitz, J.E., Fitoussi, J-P., \& Durand, M. (2019). Measuring What Counts: The Global Movement for Well-Being. New York: The New Press.

UNCDF. (2020a). Guidance Note for Immediate Responses to the COVID19 Recommended for Local Governments. Retrieved from https://www.uncdf.org/article/5477/guidance-note-covid19-localgovernments

UNCDF. (2020b). Socio-economic impact of COVID-19 on SMEs in LDCs. Retrieved from https://www.uncdf.org/smesurvey

UNCDF. (2020c). Uganda Business Impact Survey. Retrieved from https://www.uncdf.org/article/5634/uganda-business-impact-survey-2020

UNCDF. (2020d). Guiding principles and practices for urban economic recovery and resilience. Retrieved from https://www.uncdf.org/article/6196/guiding-principles-and-practices-for-urbaneconomic-recovery-and-resilience\#.X5_C7WGkn-c.twitter

UN-Habitat, UN Economic Commission for Africa, UNCDF and Shelter Afrique. (2020). COVID-19 in African cities Impacts, Responses and Policies Recommendations. Retrieved from https://www.uncdf.org/article/5732/covid-19-in-africa-cities-impacts-responses-and-policies

UN-Habitat. (2018). City Resilience Profiling Tool: Guide. Retrieved from https://urbanresiliencehub.org/wp-content/uploads/2018/10/CRPT-Guide-Pages-Online.pdf

USAID. (2011). Introduction to Disaster Risk Reduction. Retrieved from https://www.preventionweb.net/files/26081_kp1concepdisasterrisk1.pdf

World Bank. (2013). Building Urban Resilience: Principles, Tools, and Practice. Washington, DC: World Bank. 